\title{
MODELO HIDROGEOLÓGICO DO SISTEMA AQUÍFERO URUCUIA NA BACIA DO RIO GRANDE (BA)
}

\author{
HYDROGEOLOGICAL MODEL OF THE URUCUIA AQUIFER SYSTEM IN THE RIO GRANDE \\ $B A S I N(B A H I A, B R A Z I L)$
}

\author{
Roger Dias GONÇALVES ${ }^{1}$ \& Hung Kiang CHANG ${ }^{2}$ \\ (1) Laboratório de Estudo de Bacias, Universidade Estadual Paulista, UNESP, Av. 24 A no 1515, Bela Vista, Rio Claro (SP), CEP \\ 13506-900. Endereço eletrônico: rogerdias@ rc.unesp.br \\ (2) Universidade Estadual Paulista, UNESP, Av. 24 A, n ${ }^{\circ}$ 1515, Bela Vista, Rio Claro (SP), CEP 13506-900. Endereço eletrônico: \\ chang@rc.unesp.br
}

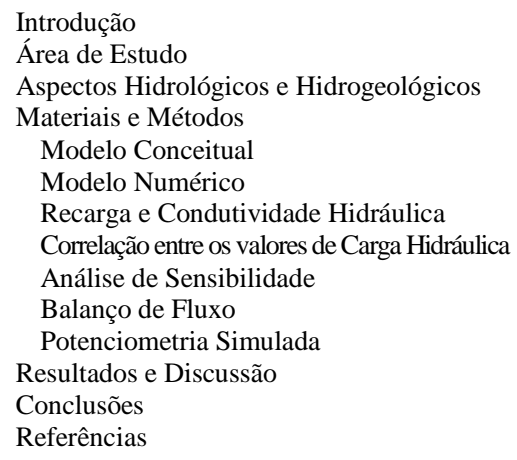

RESUMO - O Sistema Aquífero Urucuia representa um manancial estratégico no oeste baiano. Seu fluxo de base é responsável pela vazão dos principais afluentes da margem esquerda do rio São Francisco no período de estiagem, entre eles o rio Grande, seu principal afluente na Bahia. Este trabalho foca na simulação numérica em regime permanente, utilizando o método dos elementos finitos empregado no algoritmo computacional FEFLOW. Os resultados da simulação numérica evidenciaram um modelo conceitual simplificado que inclui: fluxo nulo nos limites do platô e na base do aquífero; descarga de água subterrânea nas drenagens que cortam o aquífero e que este é livre em toda a sua extensão; uma discrepância hidráulica entre as porções oeste e leste e heterogeneidade hidráulica desta última, sendo distribuídas quatro grandes zonas de condutividade hidráulica variando de $1 \times 10^{-5}$ $\mathrm{m} . \mathrm{s}^{-1}$ a $5 \times 10^{-4} \mathrm{~m} . \mathrm{s}^{-1}$; e taxas de recarga média variando aproximadamente de $20 \%$ a $25 \%$ da precipitação média nas zonas de recarga. $\mathrm{O}$ balanço hídrico calculado apresenta um valor de saída de $2,37 \times 10^{7} \mathrm{~m}^{3} \cdot \mathrm{dia}^{-1}$. O estudo confirma a grande parcela de contribuição do Sistema Aquífero Urucuia para a vazão dos rios e a influência do embasamento na porção oeste, com provável drenança de uma parcela do fluxo do aquífero.

Palavras-chave: Sistema Aquífero Urucuia, Simulação Numérica, Rio Grande, Grupo Urucuia.

ABSTRACT - The Urucuia Aquifer System represents a strategic water source in western Bahia. Its baseflow is responsible for the flow rate of the main tributaries of São Francisco river left bank in the dry season, including the Rio Grande, its main tributary in Bahia state. This work focuses on steady state numerical simulation using finite element method and computational algorithm FEFLOW. The numerical simulation results provided the conceptual model basis including a full free aquifer; null flux at plateau borders and aquifer base; hydraulic discrepancy from west to east and the hydraulic heterogeneity in the east side, performing 4 hydraulic conductivity zones varying between $1 \times 10^{-5} \mathrm{~m} \cdot \mathrm{s}^{-1}$ to $5 \times 10^{-4} \mathrm{~m} \cdot \mathrm{s}^{-1}$ and mean recharge rates varying approximately from $20 \%$ to $25 \%$ of average precipitation on recharge zones. The outflow calculated from water balance simulation is $2,37 \times 10^{7} \mathrm{~m}^{3} . \mathrm{day}^{-1}$. The study attests the great contribution of Urucuia Aquifer System to the riverflows and the basement influence in the west portion, with likely leakage of aquifer groundwater.

Keywords: Urucuia Aquifer System, Numerical Simulation, Grande River, Urucuia Group.

\section{INTRODUÇÃO}

A água é um recurso fundamental à qualidade de vida humana, e é na fase subsuperficial do seu ciclo que ocorrem controles naturais importantes para a atividade humana como filtragem, circulação e armazenamento, sendo muitas vezes atribuído um valor estratégico devido à local escassez superficial.

No oeste baiano, onde há baixa densidade de drenagem e crescente demanda de água para suprimento de fazendas e projetos de irrigação, vários rios já atingiram o limite legal máximo outorgável (Silva et al, 2005), ocasionando uma maior procura pela água subterrânea, muitas vezes sem controle.

O Sistema Aquífero Urucuia (SAU), composto pelos arenitos flúvio-eólicos neocretáceos do Grupo Urucuia (Figura 1), representa um manancial estratégico nessa região, pois aliado à crescente demanda de água para o desenvolvimento econômico, possui uma forte contribuição direta nos períodos de estiagem mediante o fluxo de base para os afluentes da margem esquerda do rio São Francisco, entre eles o rio Grande, foco deste trabalho. 
Uma importante ferramenta tanto no estudo de fluxo de água subterrânea quanto do transporte de massa (fluxo de contaminantes) é a modelagem matemática, cuja função é a representação aproximada da realidade por meio de formulações matemáticas. Uma vez que exista um modelo que represente adequadamente um determinado fenômeno ou processo, este pode ser empregado para simular diversos cenários e fazer predições.

Os métodos numéricos das diferenças finitas e dos elementos finitos são os mais usuais para a solução das equações de fluxo. O primeiro, e mais difundido, é largamente utilizado através do programa computacional MODFLOW (e suas variantes), desenvolvido pela U.S.
Geological Survey (Mcdonald \& Harbaugh, 1988). No entanto, o método dos elementos finitos, carente de conhecimento e trabalhos no território brasileiro, é empregado no presente estudo, utilizando o algoritmo computacional FEFLOW (Diersch, 2009).

Este trabalho visa o entendimento conceitual da dinâmica de fluxo de águas subterrâneas no Sistema Aquífero Urucuia na Bacia do Rio Grande através do desenvolvimento de um modelo numérico hidrogeológico, contribuindo para a pesquisa de recursos hídricos dos afluentes do Rio São Francisco, sobretudo para a quantificação e análise da sustentabilidade, de modo a auxiliar numa adequada gestão integrada dos recursos hídricos.

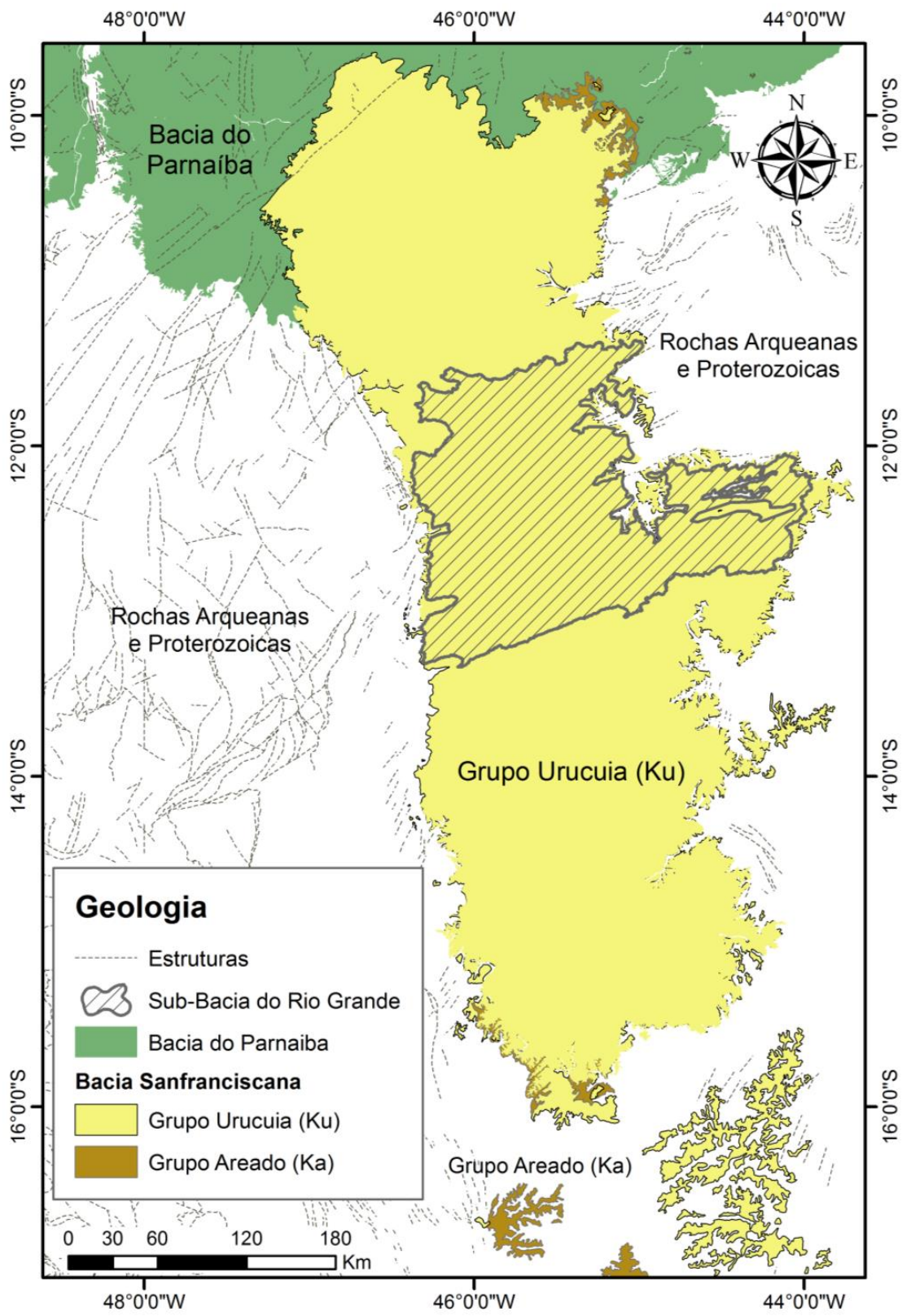

Figura 1 - Contexto geológico do Grupo Urucuia (modificado de CPRM, 2007) e a localização da área de estudo (subbacia do Rio Grande) 


\section{ÁREA DE ESTUDO}

A área de estudo se encontra na Bacia Hidrográfica do Rio Grande, localizada no oeste do Estado da Bahia, entre as latitudes $10^{\circ}$ $50^{\prime}$ e $13^{\circ} 00^{\prime}$ Sul e as longitudes $45^{\circ} 25^{\prime} \mathrm{e} 45^{\circ} 30^{\prime}$ Oeste, integrante da Bacia Hidrográfica do Rio São Francisco. No entanto, a área modelada é a Bacia do Rio Grande, sub-bacia hidrogeológica do Sistema Aquífero Urucuia (Figura 2).

$\mathrm{O}$ rio Grande é o principal afluente do rio São Francisco na Bahia e possui um regime hidrológico fortemente influenciado pela contribuição de água subterrânea, que segundo trabalhos da SRH-Bahia, chega a 70\% da vazão total do rio. Localizada na região fisiográfica média da bacia do rio São Francisco, a bacia hidrográfica do rio Grande, apesar de ser a segunda em importância para formação das vazões do rio São Francisco, apresenta sérios conflitos pelo uso da água.

A região do SAU está inserida no contexto geotectônico da bacia sanfranciscana, que é definida como a cobertura fanerozoica do Cráton do São Francisco. Campos \& Dardenne (1997b) propõem um modelo de bacia tipo sag, enquanto que Bomfim \& Gomes (2004) levantam hipóteses de bacia tipo rifte.

O SAU, na região estudada, é constituído pelos arenitos do Grupo Urucuia (Neocretáceo), subdividido nas formações Posse e Serra das Araras. A cobertura cenozoica é representada pela Formação Chapadão, presente em alúvios, colúvios ou elúvios. O embasamento é composto por rochas neoproterozóicas do Grupo Bambuí (Campos \& Dardenne, 1997a; 1997b).

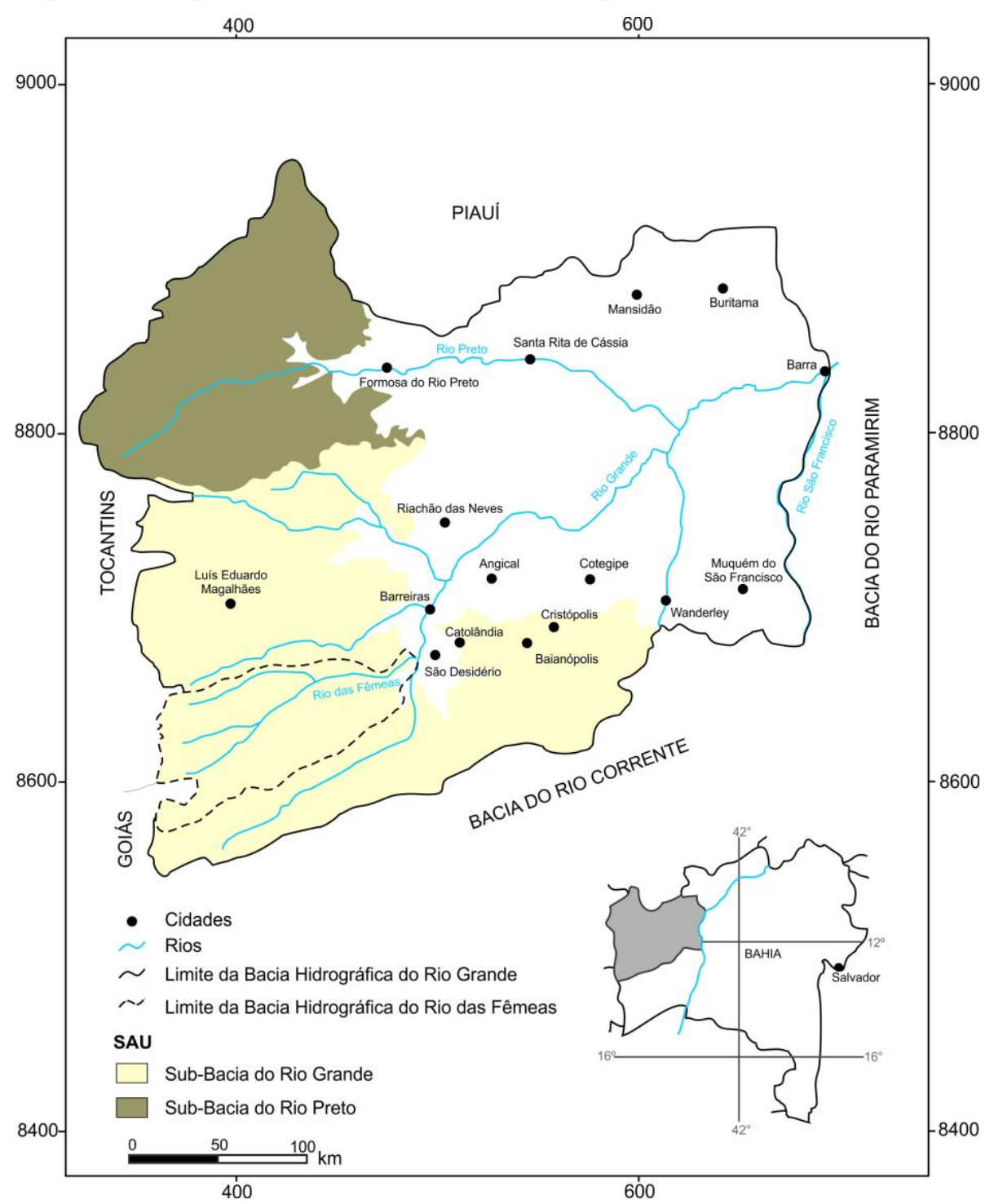

Figura 2 - Mapa de localização das bacias hidrográficas do rio Grande e do rio das Fêmeas e das sub-bacias do SAU no Estado da Bahia. 
As espessuras do Grupo Urucuia foram obtidas em trabalhos de investigação geofísica realizados no oeste baiano. No que se refere à espessura saturada (b), com uso de Sondagem Elétrica Vertical (SEV) foram obtidos valores entre $180 \mathrm{~m}$ e $400 \mathrm{~m}$ na bacia do rio do Cachorro (Lima, 2000) e; $100 \mathrm{~m}$ e $400 \mathrm{~m}$ na bacia do rio das Fêmeas (Amorim Jr., 2003; Amorim Jr. \& Lima, 2007).

No contexto de ocorrência do SAU tem-se a unidade de relevo Chapada do São Francisco, também conhecida como Chapadão do Oeste Baiano, com altitude variando de 600 a 1.000 metros. Essa unidade é a mais importante da região, em termos hidrogeológicos, por conter a área de recarga desse sistema. A unidade de relevo Patamares do São Francisco bordeja toda a extensão da área de estudo.

$\mathrm{Na}$ região do oeste baiano o clima é classificado como um clima tropical, com duas estações bem definidas, verão chuvoso, que se estende de outubro a abril, e inverno seco, de maio a setembro. A taxa anual de evaporação é de aproximadamente $1.580 \mathrm{~mm}$. A altura pluviométrica aumenta de leste para oeste na área de estudo, com médias anuais de $1.500 \mathrm{~mm}$ no extremo oeste da borda da Serra Geral de Goiás, e mínima entre $900 \mathrm{~mm}$ a $1000 \mathrm{~mm}$ na altura de Barreiras (BA). Nos meses úmidos a precipitação, é em média, quase a totalidade anual (94\%), sendo que o rio se mantém perene na estação seca, devido apenas à exsudação do Sistema Aquífero Urucuia. Esse comportamento irregular ocasiona na região períodos de excesso e déficits hídricos.

No Mapa Hidrogeológico do Brasil de DNPM/CPRM (1983), a região estudada enquadra-se na Província Hidrogeológica de São Francisco, definido como $\mathrm{Ku}$ - Aquíferos contínuos, livres e/ou confinados, constituídos de sedimentos clásticos não consolidados e consolidados, de permeabilidade média a baixa e importância hidrogeológica relativa média. Enquanto que no mapa de Domínios e Subdomínios Hidrogeológicos (CPRM, 2007 e Bonfim, 2010), a região estudada está no Domínio 2 - Bacias Sedimentares (aquífero poroso) e no Subdomínio: Bacia do Urucuia (2U) - Alta favorabilidade hidrogeológica, com vazões que podem ultrapassar 300 m3.h-1 e águas em geral de excelente qualidade química.

\section{ASPECTOS HIDROLÓGICOS E HIDROGEOLÓGICOS}

Os parâmetros hidrodinâmicos estimados a partir de testes de bombeamento nas sub-bacias do Rio Grande (rios do Cachorro e das Fêmeas) revelam relativa homogeneidade hidráulica, apresentando pequena variação dos valores de condutividade hidráulica - de até uma ordem de grandeza (Tabela 1). As discrepâncias estão nos valores obtidos por Gaspar \& Campos (2007) para o que foi chamado de aquífero livre regional, interpretados pelo método de Neuman (1975), podendo estar subestimados, segundo Gaspar (2006), uma vez que os poços utilizados não são totalmente penetrantes e atravessam somente arenitos finos.

Schuster et al. (2002) realizaram estudos hidrogeológicos na bacia do rio do Cachorro, e com base em testes de bombeamento em poços tubulares o aquífero foi dividido em: (1) inferior, semi-confinado, arenitos finos a médios (Fm. Posse), e (2) superior, freático, arenitos com níveis silicificados (Fm. Serra das Araras). Em relatório da SRH (2002), temos para a bacia do rio das Fêmeas porosidade efetiva (Sy) entre $1,25 \times 10^{-2}$ e $1,43 \times 10^{-2}$. O aquífero nesta bacia foi caracterizado como "não confinado com drenagem retardada". Gaspar (2006) analisando uma série de solos na região de recarga do SAU com ensaios de infiltração obteve valores de condutividade hidráulica vertical da ordem de 10-4 a 10-7 m.s-1, com valores médios próximos de 10-4 m.s-1.

Pimentel et al. (2000) estimaram a recarga média em 257,02 mm.ano ${ }^{-1}$, ou $20 \%$ da precipitação média, utilizando o método de separação de hidrogramas entre jan/1984 e dez/1995 a partir de estudos na bacia do rio das Fêmeas. Realizando a modelagem matemática nesta mesma bacia, Nascimento (2003) obteve um escoamento de base de 258,67 mm.ano ${ }^{-1}$, para o período de 1984 e 1995, com uma recarga média de 258,96 mm.ano ${ }^{-1}$. Gaspar (2006) obteve uma recarga de $278,98 \mathrm{~mm} . \mathrm{ano}^{-1}$, $24,10 \%$ da precipitação média, num balanço hidrogeológico, para o período de 1982 a 2002, na região de Correntina (BA). Albuquerque (2009) estimou a recarga na bacia do rio das Fêmeas em 256,53 mm.ano-1, correspondendo com $22,87 \%$ da precipitação média, pelo método automático de Rutledge \& Daniel (1994), no período de 1977 a 2007. 
Tabela 1 - Parâmetros hidrodinâmicos obtidos a partir de testes de bombeamento.

\begin{tabular}{|c|c|c|c|c|}
\hline Referência & Localização & $\mathbf{K}\left(\mathbf{m} . \mathbf{s}^{-1}\right)$ & $T\left(\mathbf{m}^{2} \cdot \mathrm{s}^{-1}\right)$ & $\mathbf{S}$ \\
\hline Schuster et al. (2002) & Rio do Cachorro & $8,8 \mathrm{E}-05$ a $2,1 \mathrm{E}-04$ & $1,3 \mathrm{E}-02$ a $5,2 \mathrm{E}-03$ & $1,1 \mathrm{E}-05$ a $2,7 \mathrm{E}-04$ \\
\hline SRH (2002) & Rio do Cachorro & $8,42 \mathrm{E}-05$ a $1,22 \mathrm{E}-04$ & $2,28 \mathrm{E}-05$ a $3,42 \mathrm{E}-05$ & \\
\hline $\operatorname{SiR}(2002)$ & Rio das Fêmeas & $6,75 \mathrm{E}-05$ a $4,39 \mathrm{E}-04$ & $1,53 \mathrm{E}-05$ a $1,78 \mathrm{E}-05$ & $3,0 \mathrm{E}-04$ a $7,5 \mathrm{E}-04$ \\
\hline Gaspar \& Campos & Livre Regional & 2,4E-07 a 1,3E-06 & 4,9E-05 a 2,7E-04 & \\
\hline (2007) & (Semi)confinado & $2,55 \mathrm{E}-05$ a $6,4-05$ & $8,91 \mathrm{E}-03$ a $2,5 \mathrm{E}-02$ & $1,01 \mathrm{E}-04$ a $1,8 \mathrm{E}-04$ \\
\hline
\end{tabular}

\section{MATERIAL E MÉTODOS}

\section{Modelo Conceitual}

Com base nas investigações geoclimáticas, hidroestratigráficas, geofísicas, resultados das perfurações dos poços, resultados dos testes de aquífero e características do fluxo subterrâneo concluídas em trabalhos anteriores, é possível estabelecer o modelo conceitual do SAU. O modelo conceitual compreende, de forma simplificada, as principais condições geológicas-hidrogeológicas do sistema aquífero, possibilitando que o modelo numérico responda adequadamente aos propósitos deste trabalho.

Nos itens abaixo estão relacionadas as premissas impostas neste modelo conceitual simplificado: (1) homogeneidade litológica e, portanto, hidráulica em toda a bacia. Justificável pela predominância dos litotipos arenosos atestada pelos trabalhos de campo e diversas descrições e ensaios de diferentes autores; (2) é admitido que todo o conjunto de unidades situadas abaixo do Urucuia é impermeável, representado, portanto, por uma condição de fluxo nulo. Justificável pela existência de um grande contraste nos valores de condutividade hidráulica entre os litotipos que compõe o aquífero e as unidades mais antigas, tendo uma conectividade hidráulica nula ou pouco expressiva. Como apontado em diversos trabalhos renomados de hidrogeologia, se existe uma diferença superior a duas ordens de grandeza em relação aos valores de condutividade hidráulica, o fluxo na base pode ser considerado paralelo a este contato, justificando a adoção de um contorno impermeável; (3) a descarga da água subterrânea se direciona exclusivamente para as drenagens que cortam o aquífero. Tal fato é justificado pelo elevado grau de dissecação destas drenagens, que confere espessuras menos expressivas do SAU nestas regiões e propiciando a convergência de fluxo de porções profundas para tais drenagens. Neste caso, admite-se que o sistema aquífero é segmentado em diversos sistemas de fluxos locais, cujos limites coincidem com os limites das bacias hidrográficas. Tal premissa é corroborada pelos valores reduzidos de condutividade elétrica da água mesmo em porções profundas do aquífero (profundidades superiores a $120 \mathrm{~m}$ ), são indicativos de um período de residência da água muito curto e a descarga ocorre dentro das drenagens presentes; (4) o aquífero é do tipo livre em toda sua extensão, inexistindo camadas confinantes expressivas na escala de trabalho adotada; (5) os limites do aquífero são representados por contornos de não-fluxo devido a sua posição topográfica mais elevada, na forma de um platô isolado. Assim é admitida a ausência de conectividade lateral com as unidades mais antigas e que o fluxo é paralelo à borda deste aquífero em suas porções limítrofes.

Em complemento à essas premissas, assumese também neste modelo conceitual que os limites norte, com a bacia do Rio Preto, e sul, com a bacia do Rio Corrente, são divisores de águas subterrâneas. Desse modo, é admitida a ausência de conectividade lateral com as subbacias confrontantes nesses limites e que o fluxo é paralelo a estes.

\section{Modelo Numérico}

A discretização do domínio do modelo foi realizada com vistas à representação detalhada do fluxo dentro da escala adotada de trabalho. Deste modo, o modelo foi discretizado em uma malha de 314.432 elementos finitos (triângulos irregulares), com 320.452 nós. A distância entre os nós variou entre $180 \mathrm{~m}$ e $90 \mathrm{~m}$, com maior 
refinamento nas bordas do modelo e nas drenagens. Não há elementos que possuem ângulo obtuso maior que $120^{\circ}$, e apenas $14,4 \%$ possuem ângulo acima de $90^{\circ}$, caracterizando uma malha de elementos finitos de boa qualidade.
A área simulada possui $27.357,6 \mathrm{~km}^{2}$ e foi discretizada em uma camada, perfazendo um volume simulado de $4.249,89 \mathrm{~km}^{3}$. Também foram representados 21 poços de observação. A configuração adotada para o modelo está representada na Figura 3.

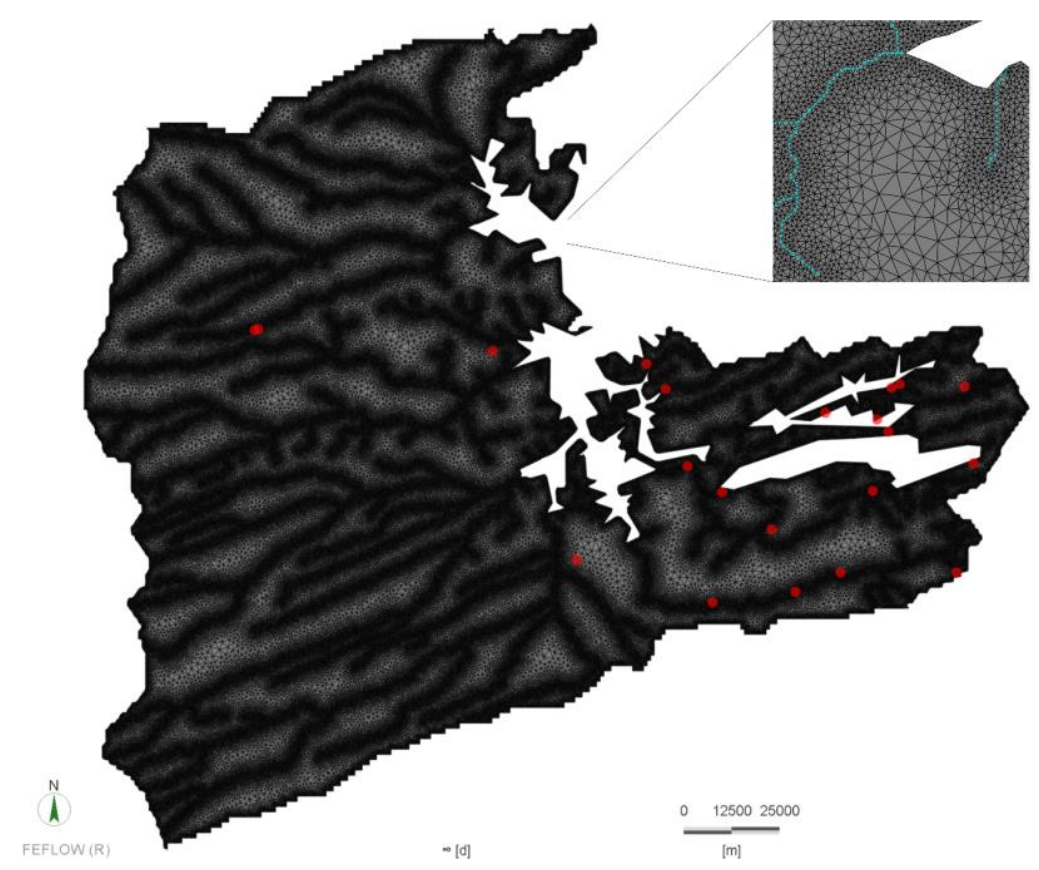

Figura 3 - Configuração da área simulada com a malha de elementos finitos com refinamento nas drenagens e nas bordas. Os pontos vermelhos representam os 21 poços de observação.

A topografia do modelo (Figura 4) foi gerada a partir de informações do modelo digital do terreno obtido da SRTM (Shuttle Radar Topography Mission). A superfície correspondente à base impermeável do modelo, representada pelo contato da base do Urucuia, foi gerada a partir da interpolação dos dados disponíveis em trabalhos anteriores, como perfis descritivos de poços e sondagem elétrica vertical. A Figura 5 mostra o resultado tridimensional do domínio simulado e os valores de espessura do modelo.

Como explanado anteriormente no modelo conceitual que o aquífero Urucuia não possui conectividade hidráulica com as unidades litoestratigráficas com as quais possui contato, foi imposta uma condição de fluxo nulo nos limites laterais e inferior deste sistema aquífero. Também foram impostas condições de contorno de carga especificada em todas as drenagens interiores que cortam o aquífero com elevado grau de dissecação e conectividade hidráulica bem definida, adotando-se a premissa que toda a saída de água se dá exclusivamente pelos inúmeros rios que cortam o aquífero. Os limites norte e sul, fronteiriços com as bacias do Rio Preto e do Rio Corrente, respectivamente, admitida a ausência de conectividade lateral e fluxo paralelo, são representados por contornos de não fluxo (Figura 6).

Após a calibração do modelo, são realizadas análises de sensibilidade para avaliação do grau de dependência dos resultados deste modelo frente a determinados parâmetros de entrada. $O$ coeficiente de sensibilidade (Xk), na forma normalizada, fornece este grau de dependência:

$X_{k}=\frac{\partial S}{\partial a_{k} / a_{k}} \approx \frac{S\left(a_{k}+\Delta a_{k}\right)-S\left(a_{k}\right)}{\Delta a_{k} / a_{k}}$

(Equação 01)

onde $\Delta S$ é a variação do RMS no valor de base $S\left(a_{\mathrm{k}}\right)$ para o novo valor $S\left(a_{k}+\Delta a_{k}\right)$ devido a mudança no parâmetro $a_{k}$. 


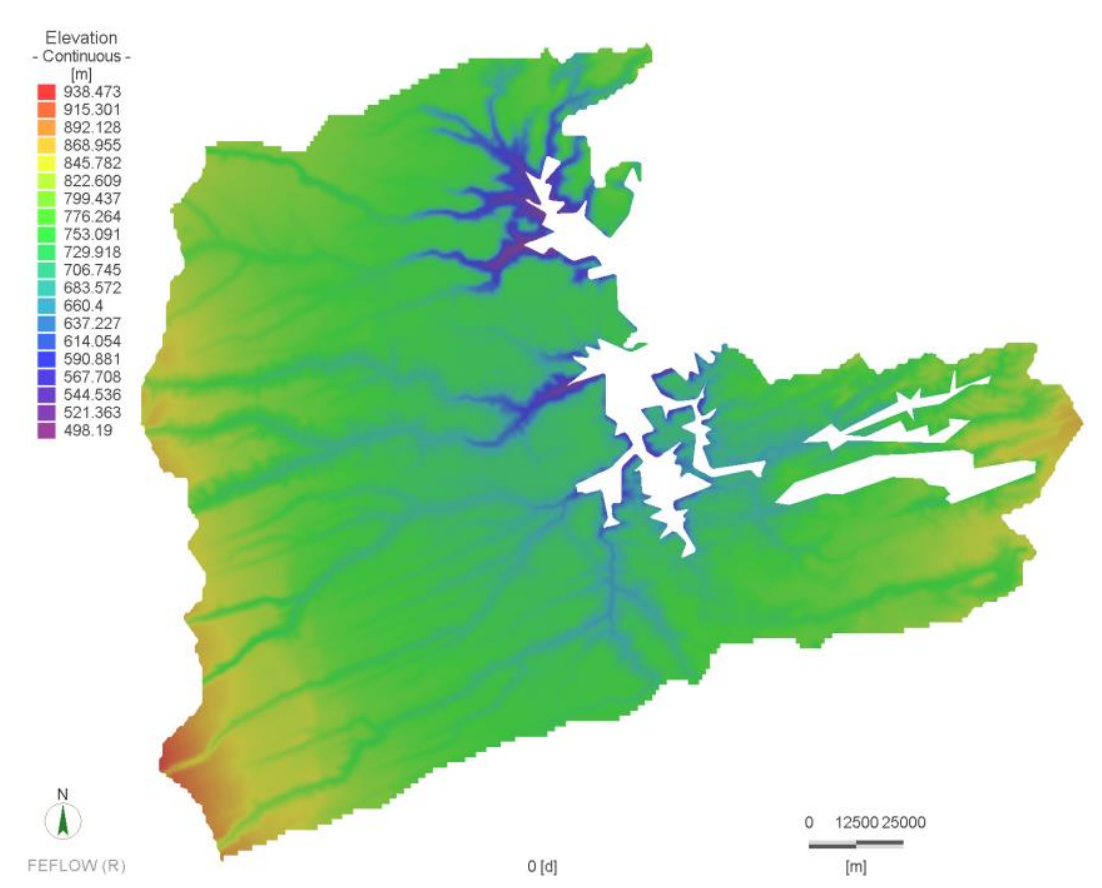

Figura 4 - Cota altimétrica do topo do modelo (SRTM).

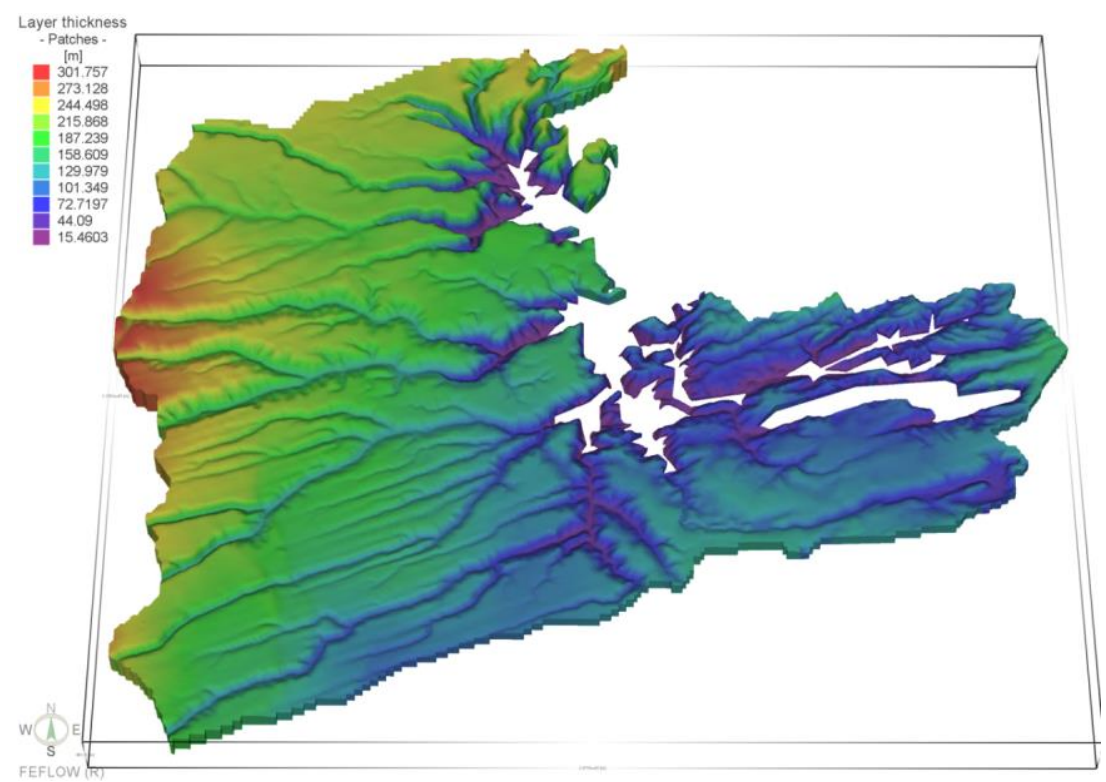

Figura 5 - Visualização em 3-D do domínio simulado, com valores de espessura (exagero vertical 30X).

\section{RESULTADOS E DISCUSSÃO}

\section{Recarga e Condutividade Hidráulica}

Trabalhos representativos na área mostram taxas de recarga média variando aproximadamente de $20 \%$ a $25 \%$ da precipitação média (Pimentel et al., 2000; Nascimento, 2003; Gaspar, 2006; Albuquerque, 2009). Deste modo, os valores de recarga do modelo variam nesta escala, sendo que nas proximidades de regiões de descarga e alto declive estes valores decrescem. As zonas de diferentes valores de recarga por precipitação foram estipuladas com base no mapa de isoietas da área (Gaspar, 2006) e na topografia, e os valores foram obtidos através das simulações (Figura 7).

Com estes valores de taxa de recarga foi possível calibrar a porção oeste da área com valores de condutividade hidráulica horizontal de $6,0 \times 10^{-5} \mathrm{~m} \cdot \mathrm{s}^{-1}$ e vertical de $3,0 \times 10^{-5} \mathrm{~m} \cdot \mathrm{s}^{-1}$. No entanto, na porção leste, após simulações em condição de regime permanente (steady state), foram determinados valores de condutividade hidráulica horizontal variando de $5,0 \times 10^{-4} \mathrm{~m} \cdot \mathrm{s}^{-1}$ a $1,0 \times 10^{-5} \mathrm{~m} \cdot \mathrm{s}^{-1}$, e vertical de $4,0 \times 10^{-4} \mathrm{~m} . \mathrm{s}^{-1}$ a $5,0 \times 10^{-6} \mathrm{~m} \cdot \mathrm{s}^{-1}$ (Figura 8). 


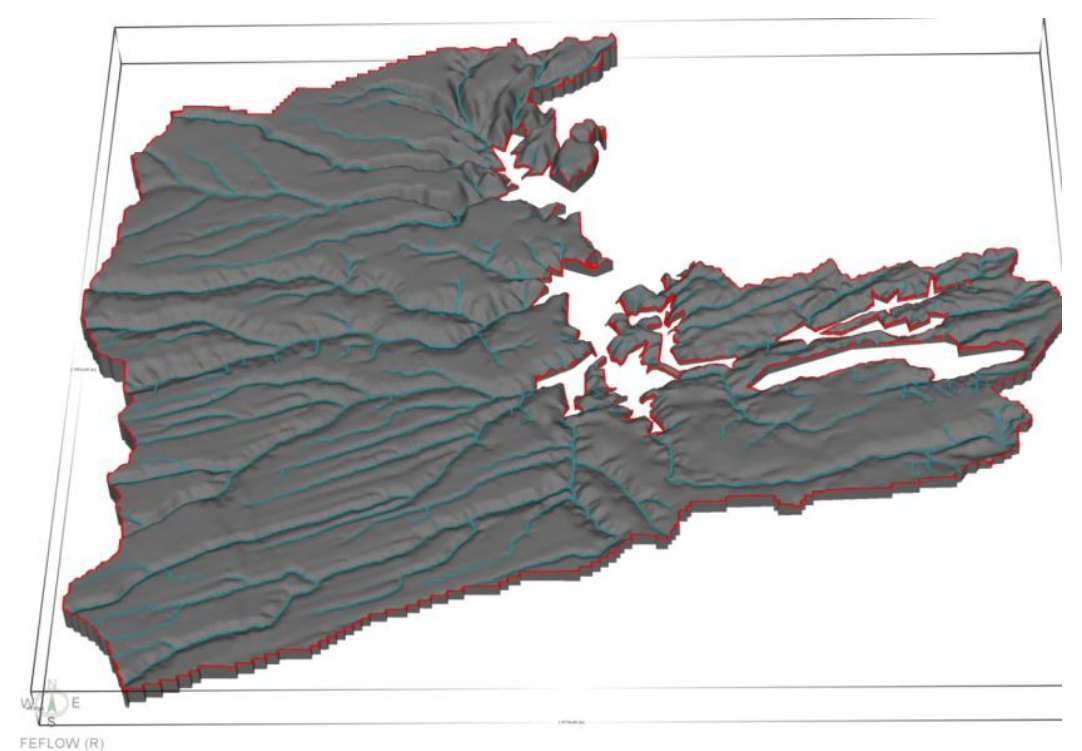

Figura 6 - Visualização em 3-D do domínio simulado com as condições de contorno representadas: em vermelho o contorno de fluxo nulo e em azul o contorno de carga especificada nas drenagens que cortam o aquífero (exagero vertical 30X).

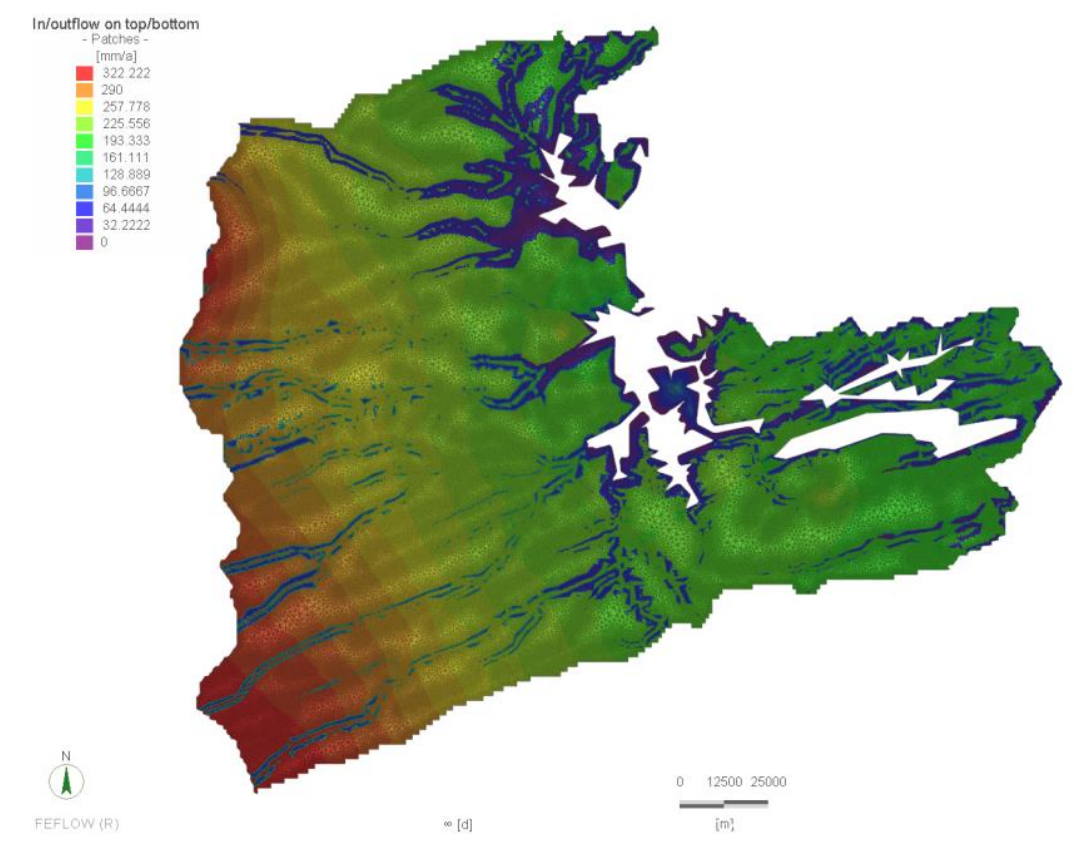

Figura 7 - Distribuição dos valores de recarga por precipitação com melhor resposta na simulação.

A análise da distribuição dos valores de condutividade hidráulica mostra além de uma clara diferença condutiva da porção leste em relação à oeste, 4 grandes zonas de condutividade hidráulica. Essas zonas são compreendidas em (K1) zona oeste, com $\mathrm{K}=6 \times 10-5 \mathrm{~m} . \mathrm{s}-1$; (K2) zona leste centro, com $\mathrm{K}=3 \times 10-4$ m.s-1; (K3) zona extremo leste, com $\mathrm{K}=5 \times 10-4 \mathrm{~m} . \mathrm{s}-1$; e (K4) zona lestenorte, com $\mathrm{K}=1 \mathrm{x} 10-5 \mathrm{~m} . \mathrm{s}-1$.

\section{Correlação entre os valores de Carga Hidráulica}

O principal critério de calibração utilizado foi a verificação dos valores de carga hidráulica reais e os calculados para o modelo. Para esta etapa foram utilizados 21 poços operados pela CERB (Companhia de Engenharia Ambiental e Recursos Hídricos da Bahia) compilados em Gaspar (2006), locados na área de interesse e com os filtros no Sistema Aquífero Urucuia (Figura 9).

A análise dos valores de carga hidráulica observados nos poços e aqueles obtidos pelas simulações (Tabela 2) a partir de gráficos de dispersão (Figura 10) permite a calibração do modelo. Atentar para os bons índices de ajustamento, como erro normalizado quadrático: Normalized RMS $=3,481 \%$, coeficiente de determinação: $\mathrm{R}^{2}=0,9844$ e coeficiente de correlação: $\rho=99,2178 \%$. 


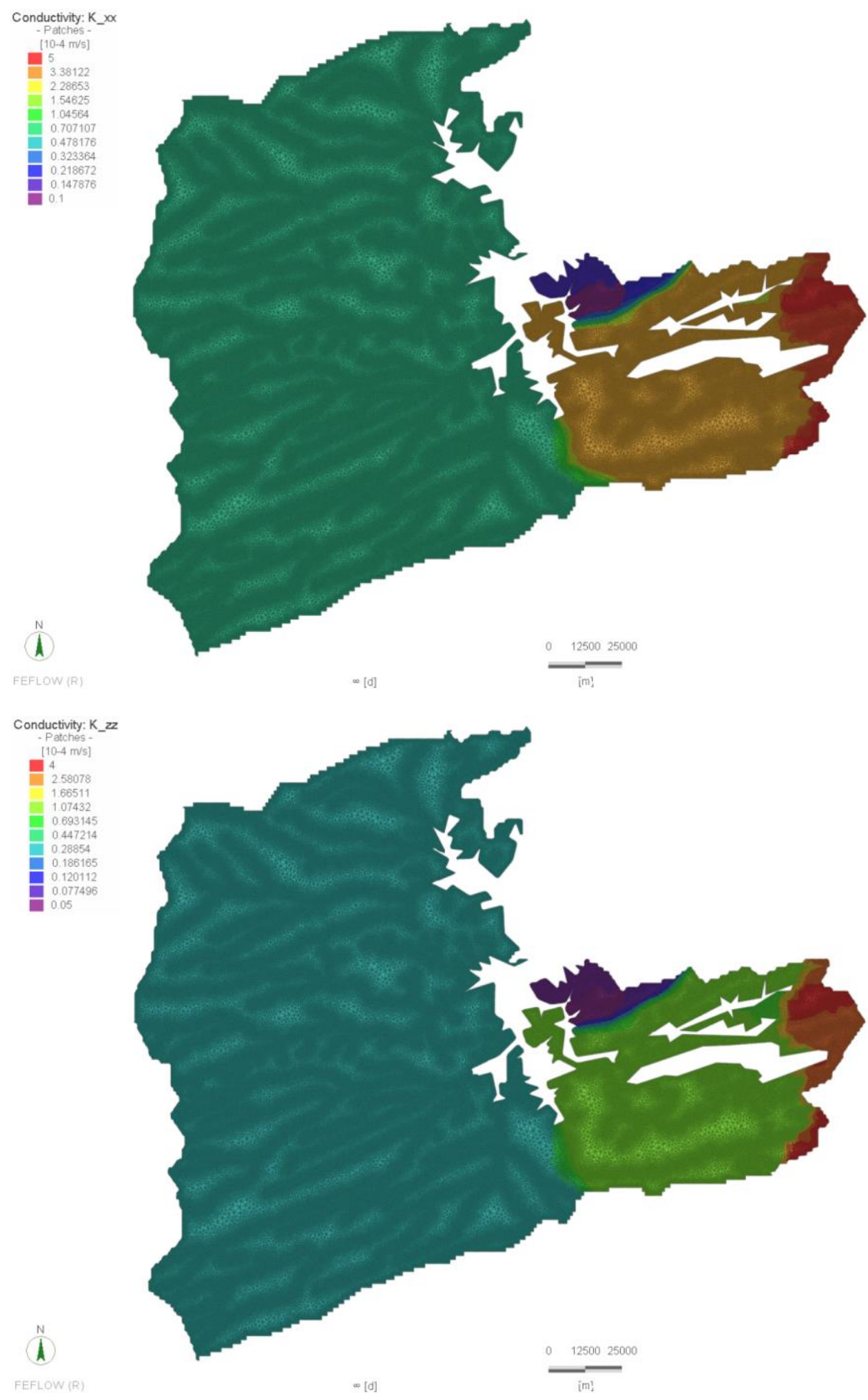

Figura 8 - Distribuição dos valores de condutividade hidráulica, horizontal e vertical, respectivamente.

\section{Análise de Sensibilidade}

Tendo em vista que o modelo calibrado é influenciado por incertezas, faz-se necessária a análise de sensibilidade a fim de ponderar a influência de parâmetros incertos no modelo, e assim estipular o grau de confiabilidade dos diversos parâmetros inseridos. Foram realizadas modificações de $20 \%$ do valor original dos parâmetros de recarga e condutividade hidráulica utilizados no modelo e submetidos a novas simulações, sendo adotado, neste caso, o critério de calibração RMS como ponderador de sensibilidade (Tabela 3 e Figura 11).

Os resultados obtidos com a modificação dos parâmetros por zonas mostram que a zona com maior sensibilidade é a K1 (zona oeste), no entanto, temos uma queda considerável do coeficiente de sensibilidade na análise dessa zona desconsiderando o poço 35 . Esse fato indica que a maior sensibilidade incide sobre a região leste dessa zona, onde está locado este poço. Nota-se ainda que a zona extremo leste (3) tem elevada sensibilidade à taxa de recarga. 


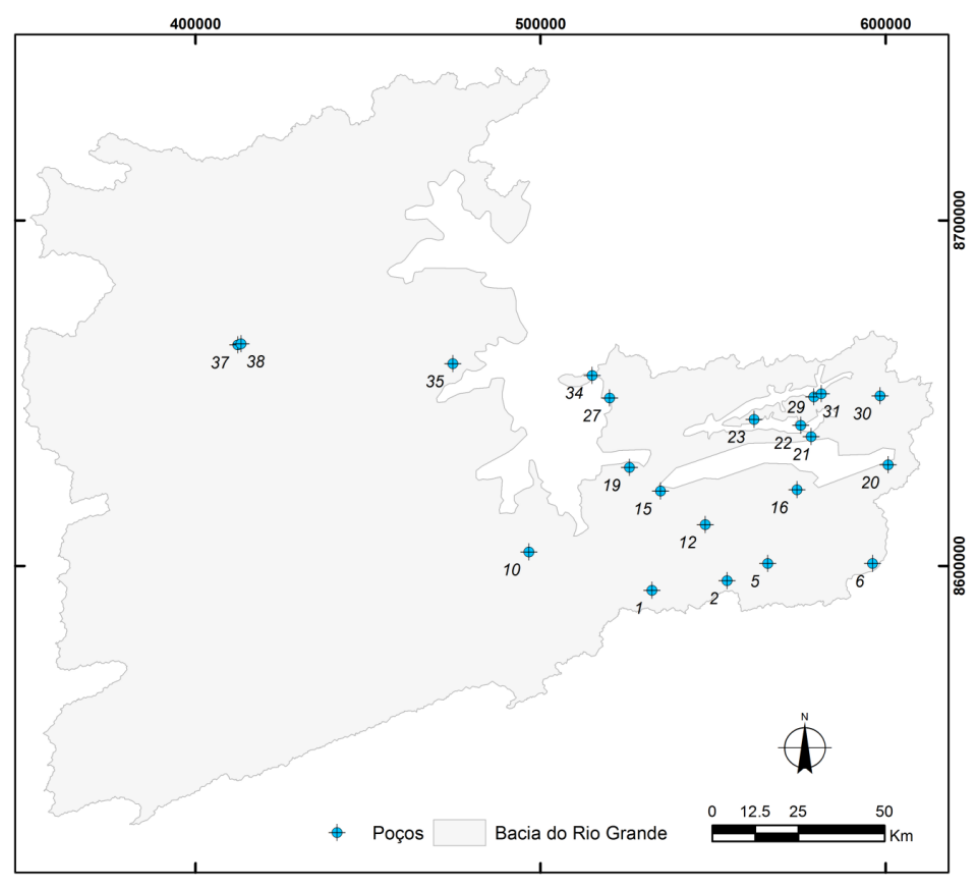

Figura 9 - Distribuição espacial dos 21 poços de observação utilizados na calibração.

Tabela 2 - Valores de carga hidráulica para os 21 poços de observação.

\begin{tabular}{|c|c|c|c|c|}
\hline POÇO & MUNICÍPIO & LOCALIDADE & $\begin{array}{l}\text { CARGA HIDR. } \\
\text { OBSERVADA (m) }\end{array}$ & $\begin{array}{l}\text { CARGA HIDR. } \\
\text { CALCULADA (m) }\end{array}$ \\
\hline 1 & SÃO DESIDÉRIO & CAMPO GRANDE & 744,76861572 & 744,717484 \\
\hline 2 & BAIANÓPOLIS & MILAGRE & 750,49969482 & 750,843477 \\
\hline 5 & BAIANÓPOLIS & LAGOA CLARA & 755,86102295 & 758,839588 \\
\hline 6 & $\begin{array}{c}\text { TABOCAS DO BREJO } \\
\text { VELHO }\end{array}$ & JUAZEIRO & 762,65673828 & 772,295319 \\
\hline 10 & SÃO DESIDÉRIO & ALVORADA & 703,99609375 & 703,671356 \\
\hline 12 & BAIANÓPOLIS & $\begin{array}{l}\text { COCOS OU VEREDA DOS } \\
\text { COCOS }\end{array}$ & 773,12579346 & 761,842354 \\
\hline 15 & BAIANÓPOLIS & COCAL DE BAIXO & 685,21508789 & 687,954685 \\
\hline 16 & $\begin{array}{c}\text { TABOCAS DO BREJO } \\
\text { VELHO }\end{array}$ & MOCAMBO & 750,74383545 & 751,277864 \\
\hline 19 & SÃO DESIDÉRIO & PORTO ALEGRE & 675,44061279 & 677,021417 \\
\hline 20 & CORIBE & FAZ. BAIXAO (JOSÉ) & 741,80322266 & 744,581067 \\
\hline 21 & $\begin{array}{c}\text { TABOCAS DO BREJO } \\
\text { VELHO }\end{array}$ & BAIXA DA CINZA & 749,47326660 & 746,084327 \\
\hline 22 & CRISTÓPOLIS & PASSAGEM DO JACARE & 737,91210938 & 739,202927 \\
\hline 23 & CRISTÓPOLIS & ENCHARCO & 704,02990723 & 707,600586 \\
\hline 27 & BARREIRAS & BEZERRO & 694,49334717 & 694,552093 \\
\hline 29 & CRISTÓPOLIS & ÁGUA DOCE & 758,07348633 & 759,972857 \\
\hline 30 & CRISTÓPOLIS & LAGOA DO OSCAR & 783,95861816 & 792,230248 \\
\hline 31 & CRISTÓPOLIS & POÇO NOVO & 767,31274414 & 763,509721 \\
\hline 34 & BARREIRAS & ALTO DA BELA VISTA & 662,79705811 & 662,537703 \\
\hline 35 & BARREIRAS & KM 30 OU CAPAO DO MEIO & 679,15557861 & 670,901746 \\
\hline 37 & $\begin{array}{l}\text { LUÍS EDUARDO } \\
\text { MAGALHÃES }\end{array}$ & SEDE & 749,01251221 & 749,412734 \\
\hline 38 & $\begin{array}{l}\text { LUÍS EDUARDO } \\
\text { MAGALHÃES }\end{array}$ & SEDE & 749,99267578 & 749,964927 \\
\hline
\end{tabular}




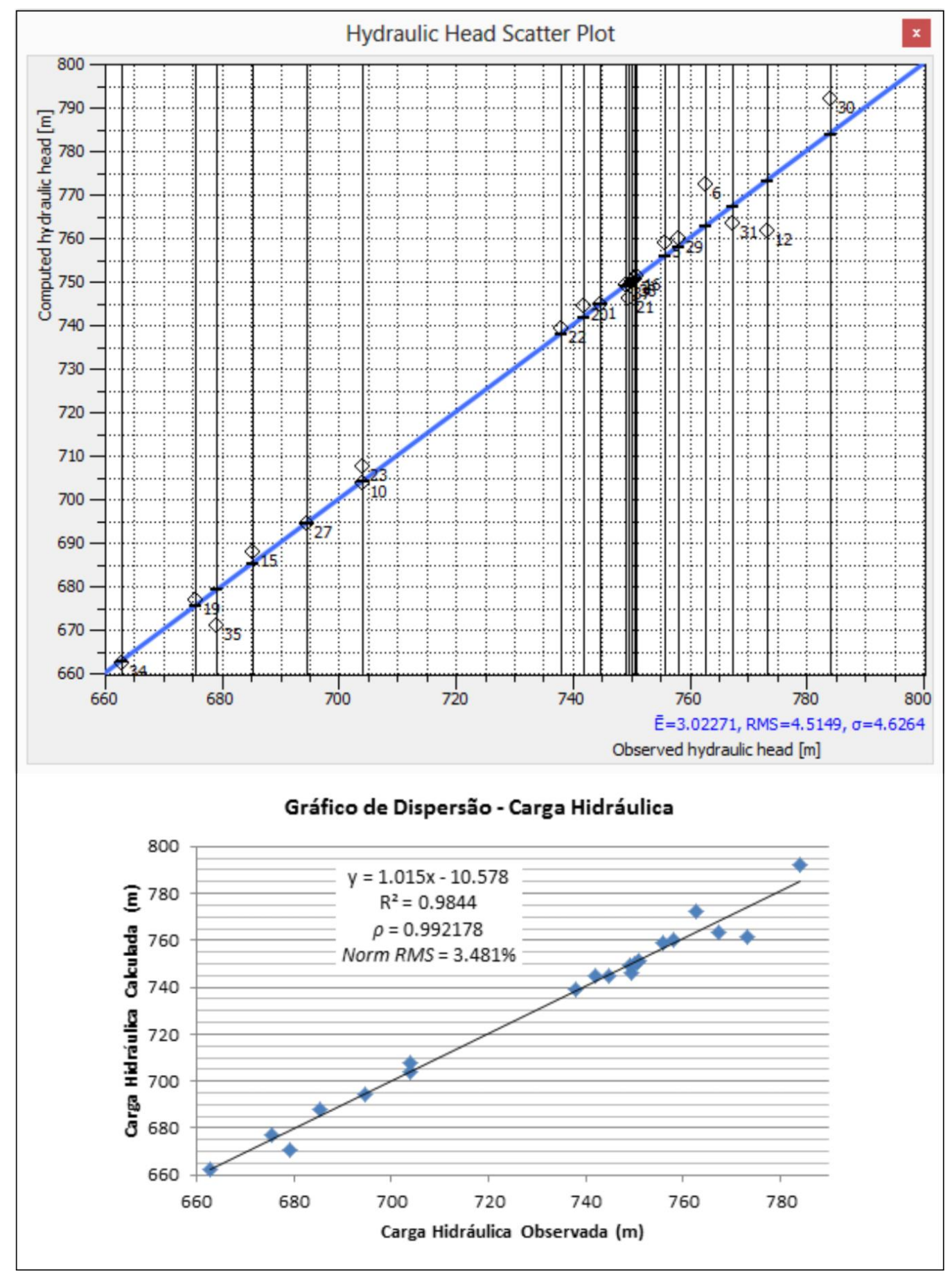

Figura 10 - Gráficos de correlação dos valores de carga hidráulica observados nos poços de observação versus os calculados pela simulação.

A análise de sensibilidade com modificação em $20 \%$ dos parâmetros em todo o domínio simulado mostra um coeficiente de sensibilidade relacionado à mudança no parâmetro de recarga $(\mathrm{Rt})$ muito superior à mudança na condutividade hidráulica $(\mathrm{Kt})$, e em relação a esta última, uma sensibilidade muito maior na horizontal (Kxy) com uma pequena contribuição da variação vertical $(\mathrm{Kz})$. No geral, é importante salientar que predominam valores de coeficiente de sensibilidade muito baixos, os quais na média resultam em erros de $0,07 \%$, e mesmo o valor mais alto (Rt) altera em $0,39656 \mathrm{~m}$ o valor do RMS, o que resulta num erro de $0,28 \%$.

Visando complementar a análise de sensibilidade, foram realizadas simulações com a supressão dos valores de recarga para avaliar a importância desse parâmetro na solução do modelo. Os resultados desta simulação (Figura 12) apresentam o valor de RMS alterado para $10,9618 \mathrm{~m}$ e um incremento de erro em $7,75 \%$. 
Tabela 3 - Resultados da análise de sensibilidade para os parâmetros de condutividade hidráulica e recarga, com alteração de $20 \%$ nos valores obtidos na calibração do modelo.

\begin{tabular}{|c|c|c|c|c|c|c|c|}
\hline Parâmetro & RMS & $\begin{array}{c}\text { RMS } \\
\text { alterado }\end{array}$ & $\begin{array}{l}\text { Coeficiente de } \\
\text { Sensibilidade }\end{array}$ & Parâmetro & RMS & $\begin{array}{c}\text { RMS } \\
\text { alterado }\end{array}$ & $\begin{array}{l}\text { Coeficiente de } \\
\text { Sensibilidade }\end{array}$ \\
\hline K1 $\left(\mathbf{m} . \mathrm{s}^{-1}\right)$ & 4,5149 & 4,76409 & 1,246 & $\mathrm{R} 1$ (mm/a) & 4,5149 & 4,71042 & 0,978 \\
\hline $\mathbf{K} 1^{*}\left(\mathbf{m} \cdot \mathrm{s}^{-1}\right)$ & 4,5149 & 4,45029 & $-0,323$ & $\mathrm{R} 1 *(\mathrm{~mm} / \mathrm{a})$ & 4,5149 & 4,51969 & 0,024 \\
\hline $\mathrm{K} 2\left(\mathrm{~m} . \mathrm{s}^{-1}\right)$ & 4,5149 & 4,56729 & 0,262 & $\mathrm{R} 2(\mathrm{~mm} / \mathrm{a})$ & 4,5149 & 4,55776 & 0,214 \\
\hline $\mathrm{K} 3\left(\mathrm{~m}^{-\mathrm{s}^{-1}}\right)$ & 4,5149 & 4,47673 & $-0,191$ & R3 (mm/a) & 4,5149 & 4,6195 & 0,523 \\
\hline $\mathrm{K} 4\left(\mathrm{~m} \cdot \mathrm{s}^{-1}\right)$ & 4,5149 & 4,55856 & 0,218 & $\mathrm{R} 4$ (mm/a) & 4,5149 & 4,5704 & 0,278 \\
\hline$K t\left(m . s^{-1}\right)$ & 4,5149 & 4,67668 & 0,809 & $\mathrm{Rt}(\mathrm{mm} / \mathrm{a})$ & 4,5149 & 4,91146 & 1,983 \\
\hline $\operatorname{Kxy}\left(m \cdot s^{-1}\right)$ & 4,5149 & 4,69923 & 0,922 & \multirow{2}{*}{\multicolumn{4}{|c|}{ obs.: * sem o poço de observação 35}} \\
\hline $\mathbf{K z}\left(\mathbf{m} \cdot \mathrm{s}^{-1}\right)$ & 4,5149 & 4,47583 & $-0,195$ & & & & \\
\hline
\end{tabular}

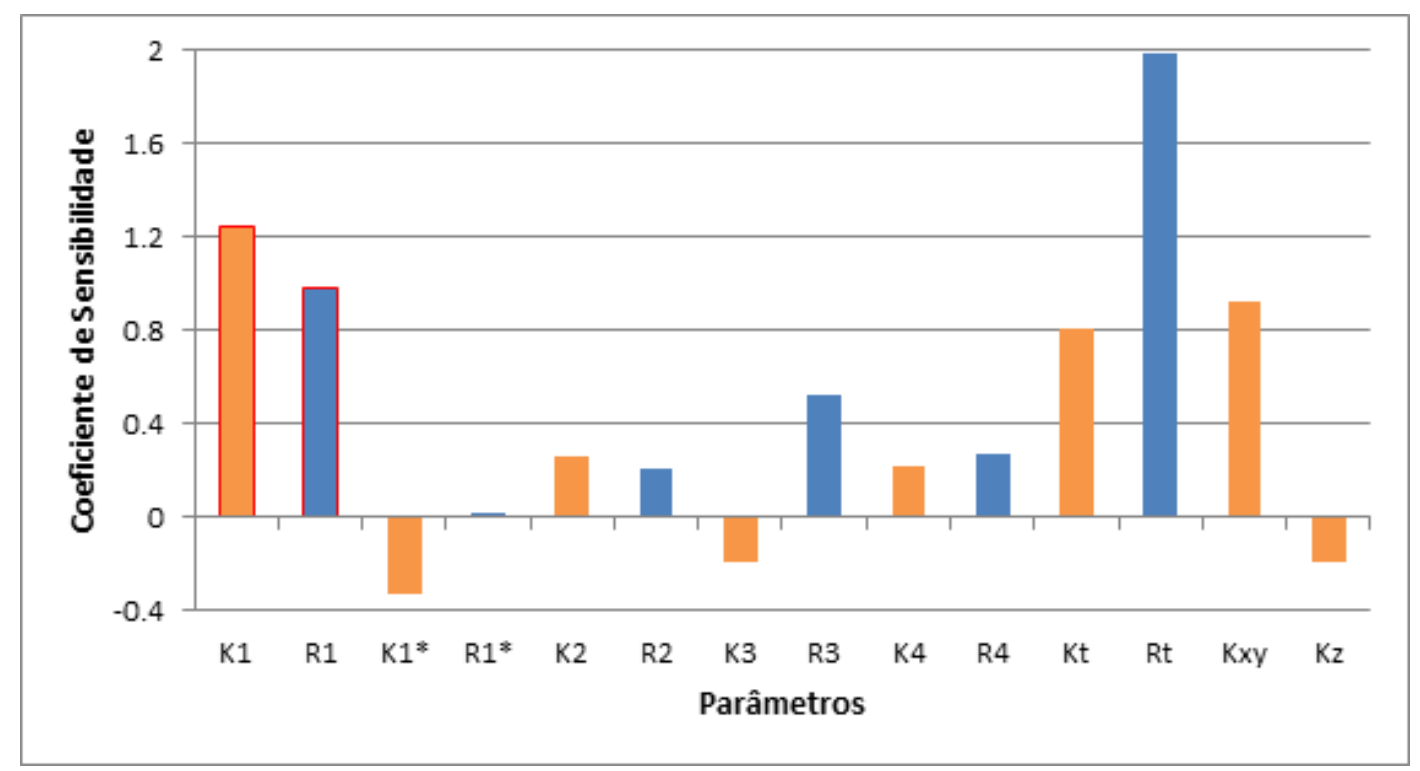

Figura 11 - Gráfico ilustrando os coeficientes de sensibilidade do critério de calibração RMS dos resíduos, encontrados na simulação, com a modificação dos parâmetros de entrada do modelo.

Diante do exposto, a análise dos resultados integrados anterior e posteriormente à calibração evidencia que os valores de recarga, apesar de não serem suficientes para a calibração do modelo sem a respectiva alteração dos valores de condutividade hidráulica, são parâmetros essenciais para a solução do modelo e sua ausência induz a um crescimento bastante acentuado do erro.

\section{Balanço de Fluxo}

Em regime permanente (steady state), o balanço de fluxo pressupõe uma condição de equilíbrio, onde o volume de água que entra no modelo é equivalente ao volume de água que sai. As simulações realizadas permitiram calcular o balanço hídrico para a sub-bacia delimitada no modelo e, deste modo, quantificar o volume de água que sai pelas condições de contorno rios e representa fisicamente o escoamento de base (Figura 13).

A somatória de entrada de água na bacia é de $23.708 .580 \mathrm{~m}^{3} /$ dia, que corresponde à recarga por precipitação $\left(15.711 .448 \mathrm{~m}^{3} /\right.$ dia) e uma participação de recarga pela drenagem (7.997.175 $\mathrm{m}^{3} / \mathrm{dia}$ ). O valor total de saída do modelo é de 
23.718.654 $\mathrm{m}^{3} / \mathrm{dia}$, que consiste na saída de água da drenagem. O balanço total simulado é de $10.031,26 \mathrm{~m}^{3} / \mathrm{dia}$, que corresponde à $0,04 \%$ do volume de água do modelo.

Uma vez que não se dispõe de informações confiáveis do número de poços operantes para fins de abastecimento e irrigação, optou-se pela sua não representação no modelo. Tendo em vista que as informações empregadas neste trabalho provêm de médias de séries históricas, o efeito da exploração do sistema aquífero foi atenuado e constituiu uma das incertezas hoje presente.

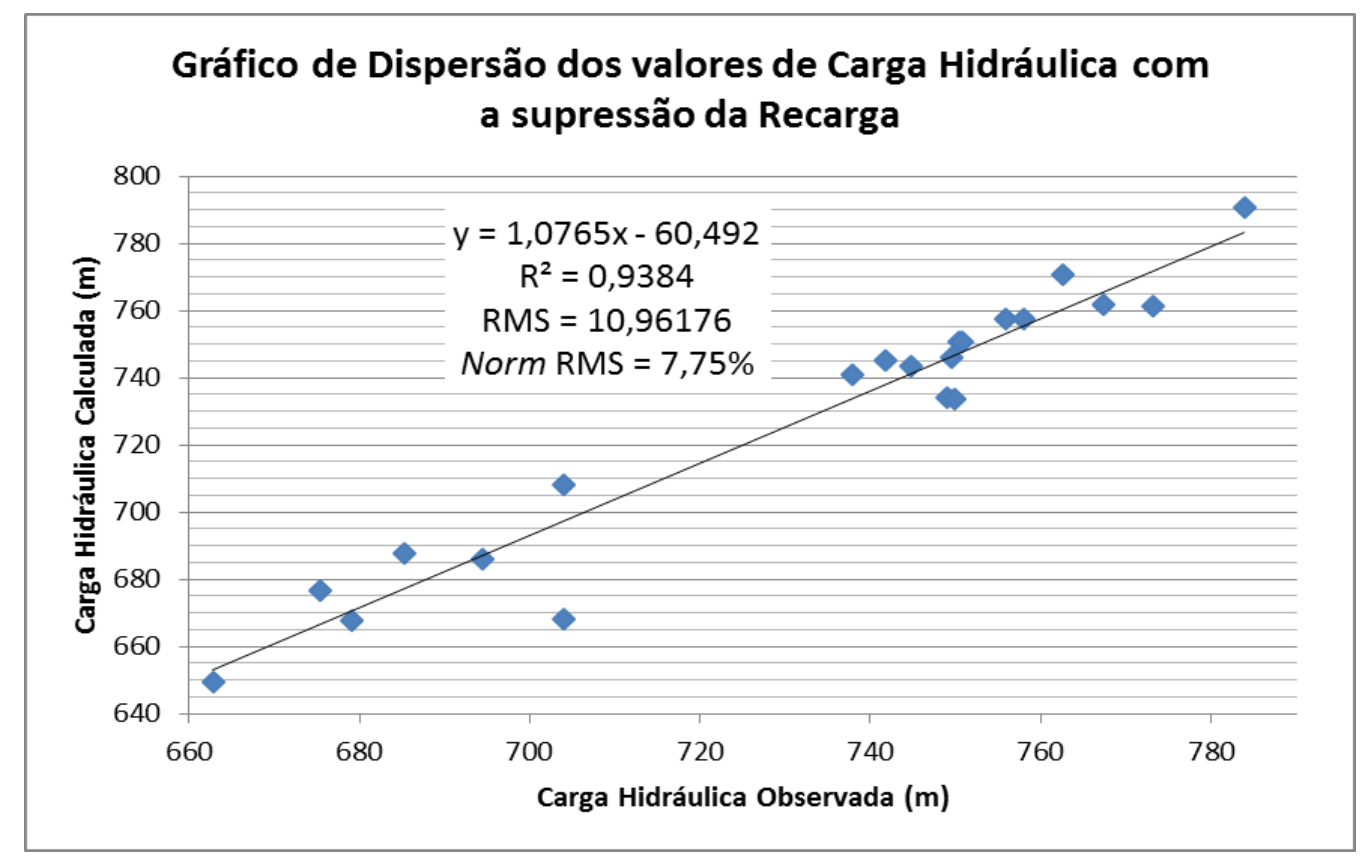

Figura 12 - Gráfico de correlação dos valores de carga hidráulica observados nos poços de observação versus os calculados pela simulação com a supressão dos valores de recarga.

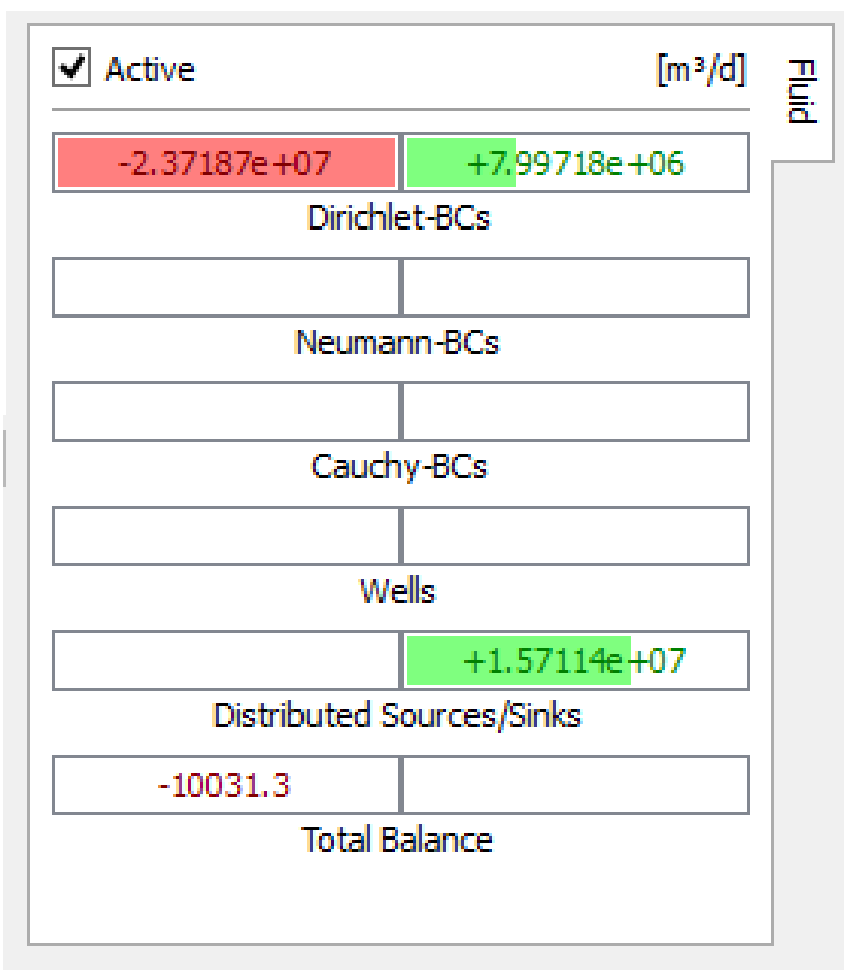

Figura 13 - Balanço hidráulico do modelo. 


\section{Potenciometria Simulada}

A Figura 14 ilustra a distribuição de carga hidráulica gerada pela simulação. É de se notar que os valores de carga hidráulica são concordantes com a conformação topográfica do Urucuia.
Numa seção vertical de direção norte-sul (perpendicular à direção principal das drenagens) traçada na região central da área em estudo (Figura 15) observa-se o comportamento da superfície potenciométrica e sua relação com a topografia da área e os principais rios que cortam o aquífero.

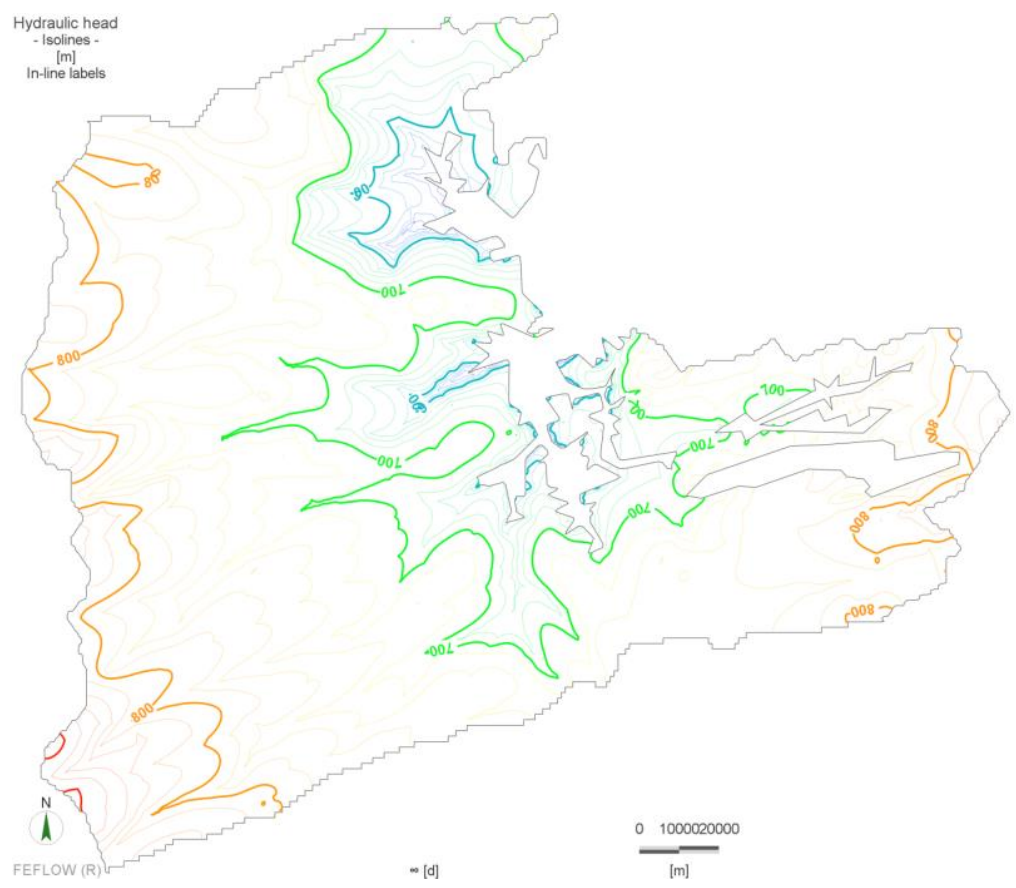

Figura 14 - Mapa potenciométrico gerado pela simulação.

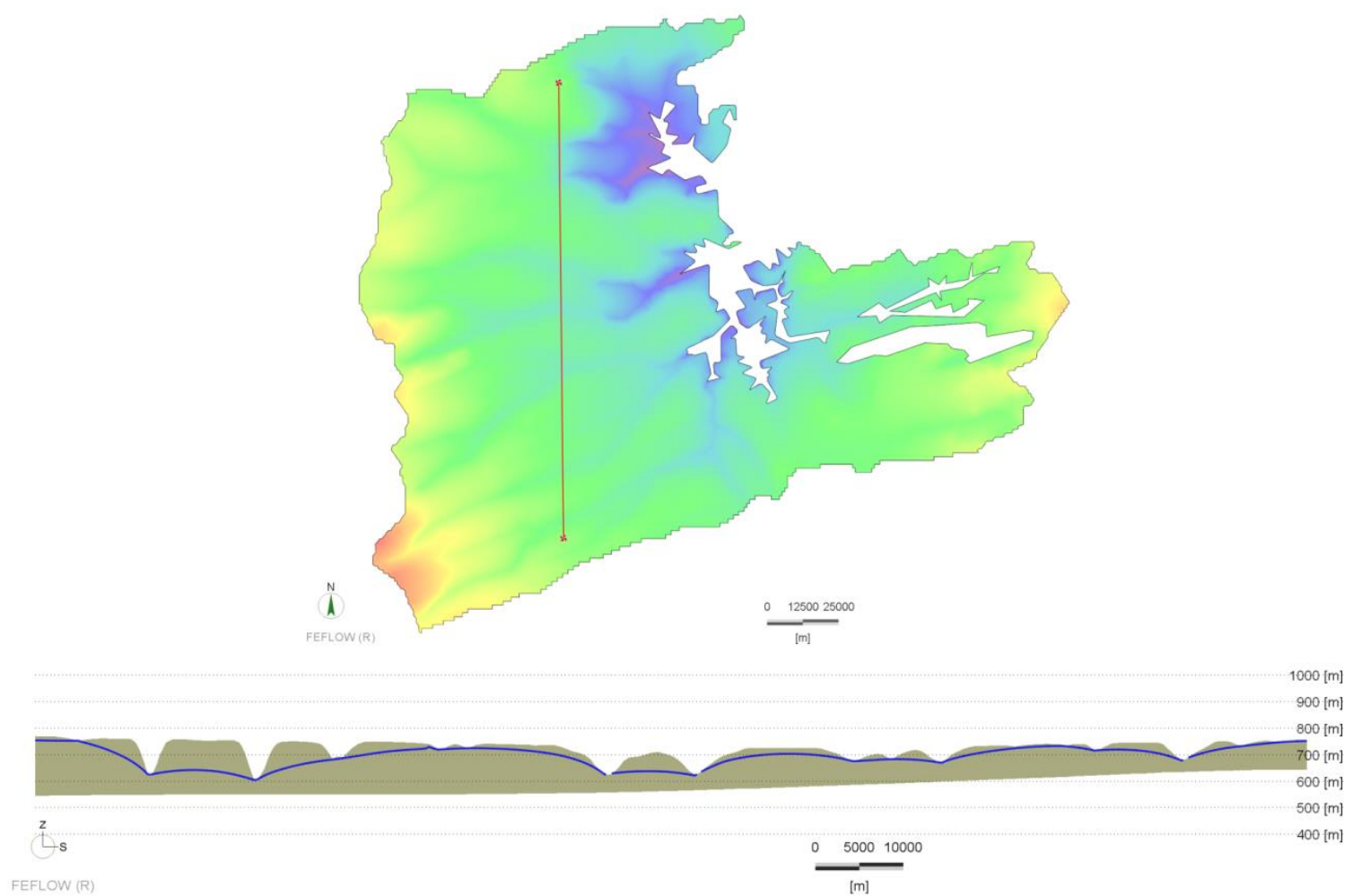

Figura 15 - Seção vertical de direção norte-sul. A linha azul representa a superfície potenciométrica (exagero vertical 30X). 


\section{CONCLUSÕES}

Acerca do modelo conceitual inicial, a premissa de homogeneidade litológica e hidráulica em toda a bacia foi utilizada devido aos inúmeros trabalhos de campo e ensaios na área. No entanto, a tentativa inicial de calibração com um valor homogêneo de condutividade hidráulica em toda a bacia mostrou-se falha, revelando assim uma variação desse parâmetro entre a porção oeste e a porção leste da bacia, esta última mais condutiva. É importante salientar que a grande maioria dos estudos do Sistema Aquífero Urucuia foram realizados na porção oeste da bacia, com destaque para os trabalhos executados nas sub-bacias do Rio das Fêmeas e do Rio do Cachorro (Pimentel et al., 2000; Schuster et al., 2002; SRH, 2002; Nascimento, 2003; Albuquerque, 2009).

A porção leste da bacia é caracterizada por apresentar: (1) declive topográfico e direção de fluxo de águas subterrâneas para oeste (oposto à porção oeste da bacia); (2) um alto do embasamento do Grupo Bambuí que recebe água do SAU na sua porção leste; (3) valores de condutividade hidráulica distintos da porção oeste da bacia; e (4) uma distribuição heterogênea dos valores de condutividade hidráulica, diferentemente da porção oeste.

No balanço hídrico calculado na simulação, o valor total de saída de água é sensivelmente maior do que a contribuição do fluxo de base do SAU calculada em trabalhos recentes na Bacia Hidrográfica do Rio Grande (ANA, 2013). Diante disso, temos que o SAU contribui com uma grande parcela no escoamento de base da bacia hidrográfica, que por sua vez abastece o Rio São Francisco, e que parte desse volume de água ao sair do Urucuia através dos rios é drenado para o embasamento metacalcário do Grupo Bambuí.

\section{REFERÊNCIAS}

ALBUQUERQUE, A.C.L.S. Estimativa de recarga da bacia do Rio das Fêmeas através de métodos manuais e automáticos. Brasília, 2009, 101 p. Dissertação (Mestrado em Engenharia Florestal) - Universidade de Brasília.

ANA - AGENCIA NACIONAL DE ÁGUAS. Estudos Hidrogeológicos na Bacia Hidrográfica do São Francisco Sistema Aquífero Urucuia/Areado e Sistema Aquífero Bambuí. 2013. http://cbhsaofrancisco.org.br/?wpfb_dl=1825. Acesso em 23 de fevereiro de 2016.

AMORIM JUNIOR, V. Avaliação hidrogeológica do Aquífero Urucuia na bacia do rio das Fêmeas usando IPResistividade. Salvador, 2003, 82 p. Dissertação (Mestrado) - Instituto de Geociências da Universidade Federal da Bahia.

AMORIM JUNIOR, V. \& LIMA, O.A.L. Avaliação hidrogeológica do Aquífero Urucuia na Bacia do Rio das Fêmeas (BA) usando resistividade e polarização induzida. Revista Brasileira de Geofísica, v. 25, n. 2, p. 117-129, 2007

BONFIM, L.F.C. \& GOMES, R.A.A.D. Aquífero Urucuia - Geometria e Espessura: Idéias para Discussão. In: CONGRESSO BRASILEIRO DE ÁGUAS SUBTERRÂNEAS, 13, 2004, Cuiabá. Anais...Cuiabá: Associação Brasileira de Águas Subterrâneas, 2004.

BONFIM, L.F.C. Mapa de domínios/subdomínios hidrogeológicos do Brasil em ambiente SIG: concepção e metodologia. In: CONGRESSO BRASILEIRO DE AGUAS SUBTERRÂNEAS, 16, 2010, São Luís: Anais... São Paulo: Associação Brasileira de Águas Subterrâneas, 2010.

CAMPOS, J.E. \& DARDENNE, M.A. Estratigrafia e Sedimentação da Bacia Sanfranciscana: Uma Revisão. Revista Brasileira de Geociências, v. 27, n. 3, p. 269-282, 1997a.

CAMPOS, J.E. \& DARDENNE, M.A. Origem e evolução tectônica da Bacia Sanfranciscana. Revista Brasileira de Geociências, v. 27, n. 3, p. 283-294, 1997b.
COMPANHIA DE PESQUISA DE RECURSOS MINERAIS. Mapa de domínios e subdomínios hidrogeológicos do Brasil. SIG. CD ROM, 2007.

DIERSCH, H.J.G. FEFLOW- Finite Element Subsurface Flow \& Transport Simulation System. Reference Manual, DHI-WASY GmbH, Berlin, 292 p. 2009.

DNPM/CPRM. Mapa hidrogeológico do Brasil. Departamento Nacional de Produção Mineral-DNPM e Companhia de Pesquisa e Recursos Minerais- CPRM. 1:5.000.000, 1983.

GASPAR, M.T.P. Sistema Aquífero Urucuia: Caracterização Regional e Propostas de Gestão. Brasília, 2006. 158 p. Tese (Doutorado) - Universidade de Brasília.

GASPAR, M. T. P. \& CAMPOS, J. E. G. O Sistema Aquífero Urucuia. Revista Brasileira de Geociências, v. 37, n. 4 suplemento), p. 216-226, 2007.

LIMA, O.A.L. Estudos Geológicos e Geofísicos do Aquífero Urucuia na Bacia do rio do Cachorro - Oeste da Bahia. Publicação da SRH-BA e UFBA, 42 p., 2000.

MCDONALD, J.M. \& HARBAUGH, A.W. MODFLOW, a modular 3D finite difference ground-water flow model. U.S. Geological Survey. Open File Report. P. 83-875, 1988.

NASCIMENTO, K.R.F. \& LIMA, O.A.L. Aquífero Urucuia: validade do modelo geoelétrico na bacia do rio das Fêmeas confirmada por novas perfurações. In: INTERNATIONAL CONGRESS OF THE BRAZILIAN GEOPHYSICAL SOCIETY 8t, 2003. Rio de Janeiro. Anais...Rio de Janeiro, 2003.

NEUMAN, S.P. Analysis of pumping test data from anisotropic unconfined aquifers considering delayed yield. Water Resources Research, v. 11, n. 2, p. 329-342, 1975.

PIMENTEL, A.L.; AQUINO, R.F. SILVA, R.C.A.; VIEIRA, C.M.B. Estimativa da recarga do aquíffero Urucuia na subbacia do rio das Fêmeas - Oeste da Bahia, utilizando separação de hidrogramas. In: CONGRESSO SOBRE APROVEITAMENTOS E GESTÃO DE RECURSOS HÍDRICOS EM PAÍSES DE IDIOMA PORTUGUÊS, 2000. Libro de Atas...Porto. p. 27 - 37 CD-ROM. 
RUTLEDGE, A.T. \& DANIEL, C.C. Testing an automated method to estimate ground-water recharge from streamflow records. Ground Water, v. 32, p. 180-189, 1994.

SCHUSTER, H.D.M; SILVA, F.F. DA; TEIXEIRA, S.L.; BATISTA, L.H.G. \& FREITAS, W.A. Estudos Hidrogeológicos do Aqüífero Urucuia no Oeste baiano para Obtenção de Parâmetros nas outorgas de mananciais Subterrâneos. In: CONGRESSO BRASILEIRO DE ÁGUAS SUBTERRÂNEAS, 12, Santa Catarina. Resumos...Santa Catarina: Associação Brasileira de Águas Subterrâneas, CDROM. 2002.

SILVA, F.F. DA; NETO, A.V.L; CARDOSO. E.R. SCHUSTER, H.D.M. Aplicação da modelagem matemática no uso conjunto água superficial e subterrânea para a gestão de recursos hídricos no oeste do Estado da Bahia. In: SIMPÓSIO DE RECURSOS HÍDRICOS DA
AMAZÔNIA, 2, 2005, Palmas. Resumos...Palmas: Associação Brasileira de Recursos Hídricos, 2005.

SUPERINTENDÊNCIA DE RECURSOS HÍDRICOS BAHIA. Projeto de Gerenciamento Integrado das Atividades Desenvolvidas em Terra na Bacia do São Francisco (ANA/GEF/PNUMA/OEA). Uso Conjunto das Águas Superficiais e Subterrâneas da Sub- Bacia do Rio das Fêmeas - BA. Relatório final de avaliação dos parâmetros hidrodinâmicos do Aquífero Urucuia - BA, 2002.

Manuscrito recebido em 24 de fevereiro de 2016 Revisado e aceito em 7 de novembro de 2016 